\title{
Analyzing neonatal deaths in Zimbabwe using box-jenkins arima models
}

\author{
Dr. Smartson P. Nyoni ${ }^{1}$, Mr. Thabani Nyoni ${ }^{2}$ \\ ${ }^{I}$ ZICHIRe Project, University of Zimbabwe, Harare, Zimbabwe \\ ${ }^{2}$ Department of Economics, University of Zimbabwe, Harare, Zimbabwe \\ Email:_smartson_p@gmail.com
}

\begin{abstract}
Using annual time series data on neonatal deaths in Zimbabwe from 1966 to 2018, we model and forecast number of neonatal deaths over the next 25 years using the Box - Jenkins ARIMA technique. Diagnostic tests such as the ADF tests show that Neonatal Deaths (ND) series is I (2). Based on the AIC, the study presents the ARIMA $(8,2,0)$ model as the optimal model. The diagnostic tests further indicate that the presented model is stable and its residuals are stationary in levels. The results of the study reveal that the numbers of neonatal deaths per year are expected to decline sharply in the next 25 years. In order to keep on reducing neonatal deaths in Zimbabwe, the study offered a four-fold policy prescription.
\end{abstract}

Keywords: neonatal deaths, Zimbabwe, model.

\section{INTRODUCTION}

Neonatal death can be defined as the number of neonates dying before reaching 28 days of age (Usman et al. 2019). The first 2 days after birth account for over $50 \%$ neonatal deaths, while the first week of life accounts for over 75\% of all neonatal deaths (Carlo \& Travers, 2016). Actually, the risk of neonatal death is highest in the first 24 hours of life (Nouri et al., 2013). In fact, 2.6 million children died in the first month of life in 2016 - nearly 7000 newborn deaths every day - most of which occurred in the first week, with about 1 million dying on the first day and close to 1 million dying within the next 6 days (UNICEF, 2017). The major causes of neonatal deaths are birth asphyxia, prematurity, sepsis as well as congenital malformation (Carlo \& Travers, 2016). Thus, neonatal deaths are an indicator of healthcare systems in a country (Babaei et al. 2018) in the sense that neonatal deaths reveal the health of children and development of the economy and culture of a country or region (Chengye, 2012). Interestingly, neonatal deaths are preventable (Tachiwenyika et al., 2011). In order to enhance the prevention of neonatal deaths, modeling and forecasting neonatal deaths is critical, especially in developing countries such as Zimbabwe where neonatal deaths are still prevalent in large numbers. Therefore, this paper, will go a long way in uncovering the dynamics of neonatal deaths in Zimbabwe and consequently shed more light on health policy formulation.

\subsection{OBJECTIVES OF THE STUDY}

i. To investigate the years during which neonatal deaths peaked in Zimbabwe.

ii. To forecast the number of neonatal deaths for the out-of sample period.

iii. To examine the pattern of neonatal deaths for the out-of-sample period.

\subsection{RELEVANCE OF THE STUDY}

Neonatal death is still a major public health problem worldwide and accounts for more than $60 \%$ of newborn deaths before their first birthday (UNICEF, 2008). Of the world's 7.7 million deaths in those aged younger than 5 years, 3.1 million are neonatal deaths (Rajaratnam et al. 2010). Approximately $99 \%$ of these neonatal deaths occur in low and middle - income countries, mostly in sub-Saharan Africa (Lawn et al. 2005) including Zimbabwe which continues to bear a heavy burden of neonatal mortality (Ministry of Health and Child Care, 2007). This study seeks to examine and forecast the number of neonatal deaths in Zimbabwe. In order to reduce the numbers of neonatal deaths to zero, there is need for reliable forecasts that will act as a guiding tool for policy makers in the health sector; hence, the need for this study.

\section{LITERATURE REVIEW}

Sarpong (2013) modeled and forecasted maternal mortality ratio (MMR) at the Okomfo Anokye Teaching Hospital in Kumasi, Ghana, from the year 2000 to 2010; using ARIMA models and found out that the ARIMA $(1,0,2)$ model was optimal for forecasting quarterly MMR at Okomfo Anokye Teaching Hospital. Ezeh 
et al. (2014) analyzed the determinants of neonatal mortality in Nigeria using the Cox Regression model and found out that a higher birth order of newborns with a short birth interval of less or equal to 2 years and newborns with a higher birth order with a longer birth interval of greater than 2 years were significantly associated with neonatal mortality.

Nyoni (2019) modeled and forecasted maternal deaths in Zimbabwe using annual time series data covering the period 1990 - 2015 and applied the Box-Jenkins ARIMA models and basically found out that in the next decade (2016-2025), maternal deaths will increase. In another Zimbabwean study, Chaibva et al. (2019) analyzed stillbirths and neonatal deaths in Mutare district: the study conducted a retrospective review of 346 patient records, of women who delivered at Sakubva Hospital and those reffered for Mutare district facilities to Mutare Provincial Hospital, between January and June 2014 and then used descriptive statistics to explore the contributors to stillbirths and neonatal deaths in Mutare. Their results basically show that of the 346 women, $15.6 \%$ (i.e. 54) experienced an adverse pregnancy outcome (stillbirth or neonatal death). Their results also indicate that contributing factors to adverse pregnancy outcomes included birthweight, gestational age, delivery complications and delivery methods. In yet another, most recent Zimbabwean study, Nyoni \& Nyoni (2020) analyzed monthly time series data on neonatal death cases at Chitungwiza Central Hospital $(\mathrm{CCH})$ from January 2013 to December 2018 using Box-Jenkins SARIMA models and found out that there will be a slow but steady decrease in neonatal deaths at CCH over the out-of-sample period, that is, January 2019 to December 2020.

Mishra et al. (2019) forecasted Infant Mortality Rates (IMR) in India using ARIMA models. The forecast of the sample period (1971-2016) indicated accuracy by the selected ARIMA $(2,1,1)$ model. The post sample forecast with the ARIMA $(2,1,1)$ model revealed a decreasing trend of IMR (2017-2025). The forecast IMR for 2025 was found to be 15/1000 live births. Khan et al. (2019) modeled and forecasted IMR of Asian countries using the log-log regression and ARIMA models and found out that there was a negative correlation between IMR and GDP (PPP). Secondary data of IMR and GDP (PPP) from 1980 to 2015 was analyzed and forecast was done from 2016 to 2025: the AR (1) model was found for all countries except Japan and Nepal for which the ARIMA $(1,1,1)$ model was found suitable. Usman et al. (2019) analyzed the incidence of the rate of neonatal mortality in Nigeria using ARIMA models. Their trend plot of the incidence indicated that there was a steady decrease in the incidence rate over the years. The ARIMA $(1,1,1)$ model was found to be the optimal model. The time series analysis also revealed that the neonatal mortality rate has reduced by $17.8 \%$ from $51.7 \%$ in the year 1990 to $33.9 \%$ in the year 2017. This paper follows the leads of Usman et al. (2019) and is the first country-specific study which has forecasted neonatal deaths in Zimbabwe.

\section{ARIMA Models}

\section{MATERIALS \& METHODS}

Autoregressive Integrated Moving Average (ARIMA) models deliver more accurate forecasts than econometric techniques (Song et al., 2003b). In fact, ARIMA models perform better than multivariate models in forecasting (du Preez \& Witt, 2003). ARIMA models were developed by Box \& Jenkins (1970) and their approach of identification, estimation and diagnostics is based on the principle of parsimony (Asteriou \& Hall, 2007). The generalized ARIMA (p, d, q) model can be represented by a backward shift operator as:

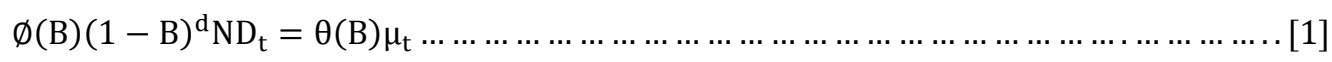

Where the autoregressive (AR) and moving average (MA) characteristic operators are:

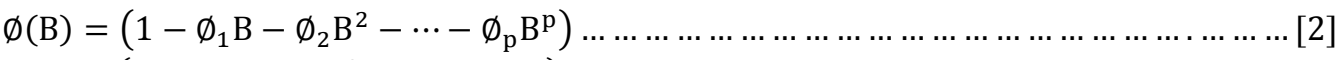

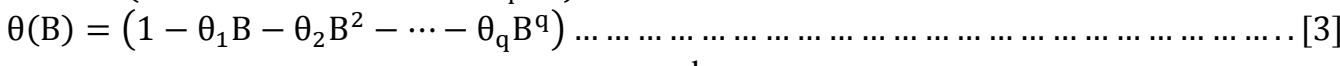

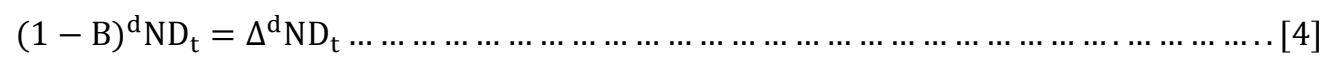

Where $\emptyset$ the parameter estimate of the autoregressive component is, $\theta$ is the parameter estimate of the moving average component, $\Delta$ is the difference operator, $\mathrm{d}$ is the difference, $\mathrm{B}$ is the backshift operator and $\mu_{\mathrm{t}}$ is the disturbance term.

\section{The Box - Jenkins Methodology}

The first step towards model selection is to difference the series in order to achieve stationarity. Once this process is over, the researcher will then examine the correlogram in order to decide on the appropriate orders of the AR and MA components. It is important to highlight the fact that this procedure (of choosing the AR and MA components) is biased towards the use of personal judgement because there are no clear - cut rules on how to decide on the appropriate AR and MA components. Therefore, experience plays a pivotal role in this regard. The next step is the estimation of the tentative model, after which diagnostic testing shall follow. Diagnostic 
checking is usually done by generating the set of residuals and testing whether they satisfy the characteristics of a white noise process. If not, there would be need for model re - specification and repetition of the same process; this time from the second stage. The process may go on and on until an appropriate model is identified (Nyoni, 2018c).

\section{Data Collection}

This study is based on 53 observations of annual total Neonatal Deaths (ND) in Zimbabwe. All the data was gathered from the World Bank online database.

\section{Diagnostic Tests \& Model Evaluation Stationarity Tests: Graphical Analysis}

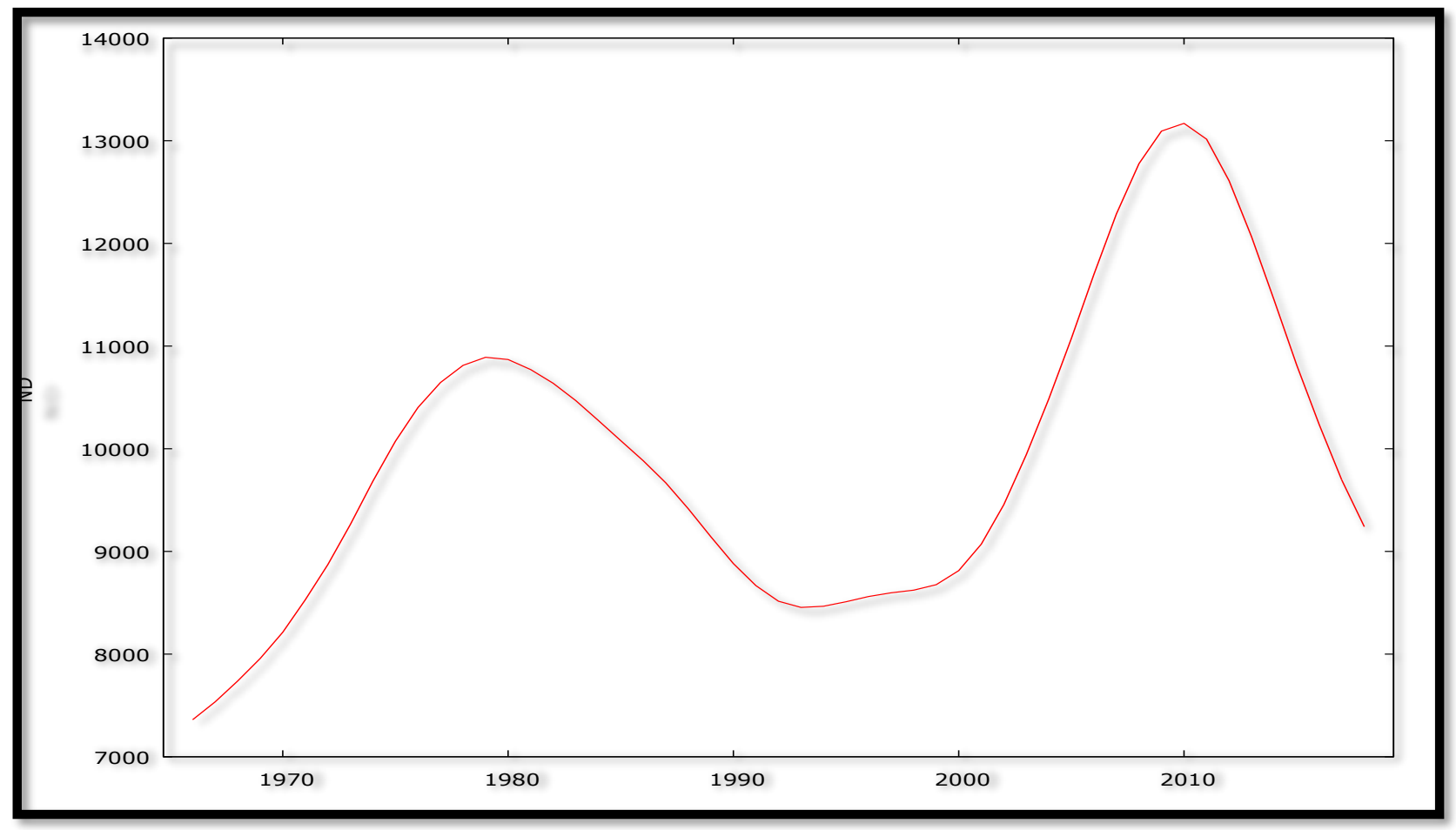

Figure 1

Figure 1 above indicates that the ND series is not stationary since it follows a particular trend over the period 1966 to 2018. This basically implies that the mean and varience of the ND series is changing over time. Between 1966 and 1980, neonatal deaths were on the rise in Zimbabwe (then Rhodesia). This could be attributed to the liberation war (between black majority and white minority) that was taking place in Rhodesia. Soon after Zimbabwe's independence, the country inherited a health system which was well functioning and given there was political stability; neonatal deaths dropped significantly from as high as 10869 deaths in 1980 to as low as 8455 in 1993. The disastrous macroeconomic reforms over the period $1990-2000$, largely contributed to poor performance of the health sector and hence neonatal healthcare service delivery was worse off. The following "lost decade", that is; 2000 to 2010 was a completely lost decade, as noted by Kanyenze et al. (2017), as it was characterized by gross macroeconomic mismanagement, hyperinflation and excessive unemployment. This period was a huge blow to the health sector in Zimbabwe and this could be an explanation as to why neonatal deaths had to sky-rocket over the period 2000 to 2010. Thereafter, the numbers of neonatal deaths started going down gradually. This could be attributed to macroeconomic stability that was largely brought about by the introduction of the United States Dollar (USD) as the official currency, following the rejection of the Zimbabwean dollar which had lost value. When the economy is performing, the government and its partners are able to mobilize resources for the health sector and this improves health service delivery. When the economy is not performing, health workers migrate to greener pastures just like what happened during the lost decade. The government is usually not able to capacitate and renovate existing healthcare facilities if the economy is not performing. In order to determine the order of integration of the ND series shown above, the study will employ correlogram analyses along with the Augmented-Dickey-Fuller (ADF) test. 


\section{The Correlogram in Levels}

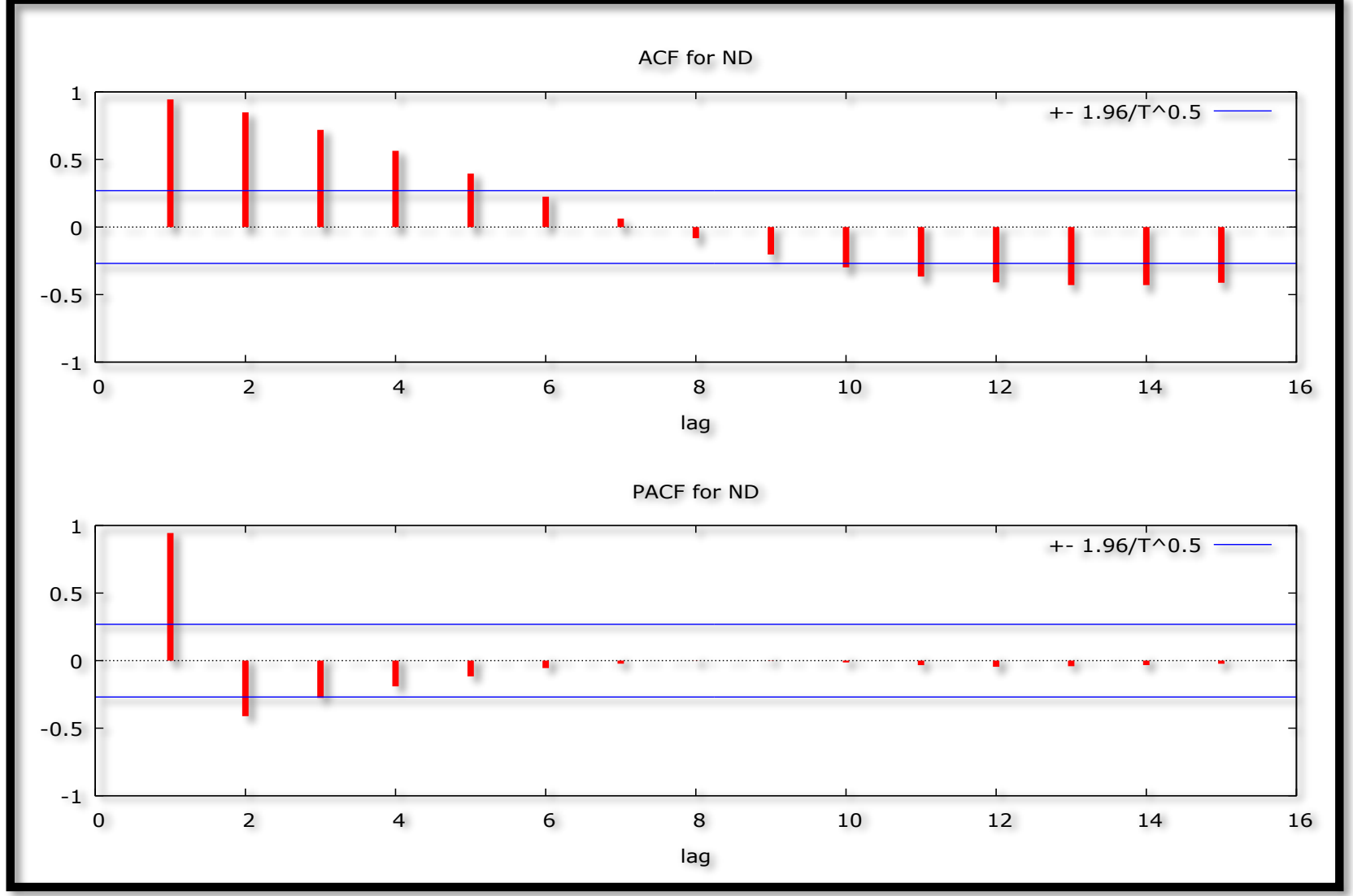

The ADF Test

Figure 2

Table 1: Levels-intercept

\begin{tabular}{|l|l|l|l|l|l|}
\hline Variable & ADF Statistic & Probability & Critical Values & Conclusion \\
\hline ND & -2.929920 & 0.0493 & -3.574446 & @ 1\% & Not stationary \\
\hline & & -2.923780 & @ 5\% & Stationary \\
\hline & & 2.599925 & @ 10\% & Stationary \\
\hline
\end{tabular}

Table 2: Levels-trend \& intercept

\begin{tabular}{|l|l|l|l|l|l|}
\hline Variable & ADF Statistic & Probability & Critical Values & Conclusion \\
\hline ND & -3.631186 & 0.0375 & -4.161144 & @ 1\% & Not stationary \\
\hline & & -3.506374 & $@ 5 \%$ & Stationary \\
\hline & & -3.183002 & $@ 10 \%$ & Stationary \\
\hline
\end{tabular}

Table 3: without intercept and trend \& intercept

\begin{tabular}{|c|c|c|c|c|c|}
\hline Variable & ADF Statistic & Probability & \multicolumn{2}{|c|}{ Critical Values } & Conclusion \\
\hline ND & 0.305604 & 0.7702 & -2.613010 & @ 1\% & Not stationary \\
\hline & & & -1.947665 & @5\% & Not stationary \\
\hline & & & -1.612573 & @ 10\% & Not stationary \\
\hline
\end{tabular}




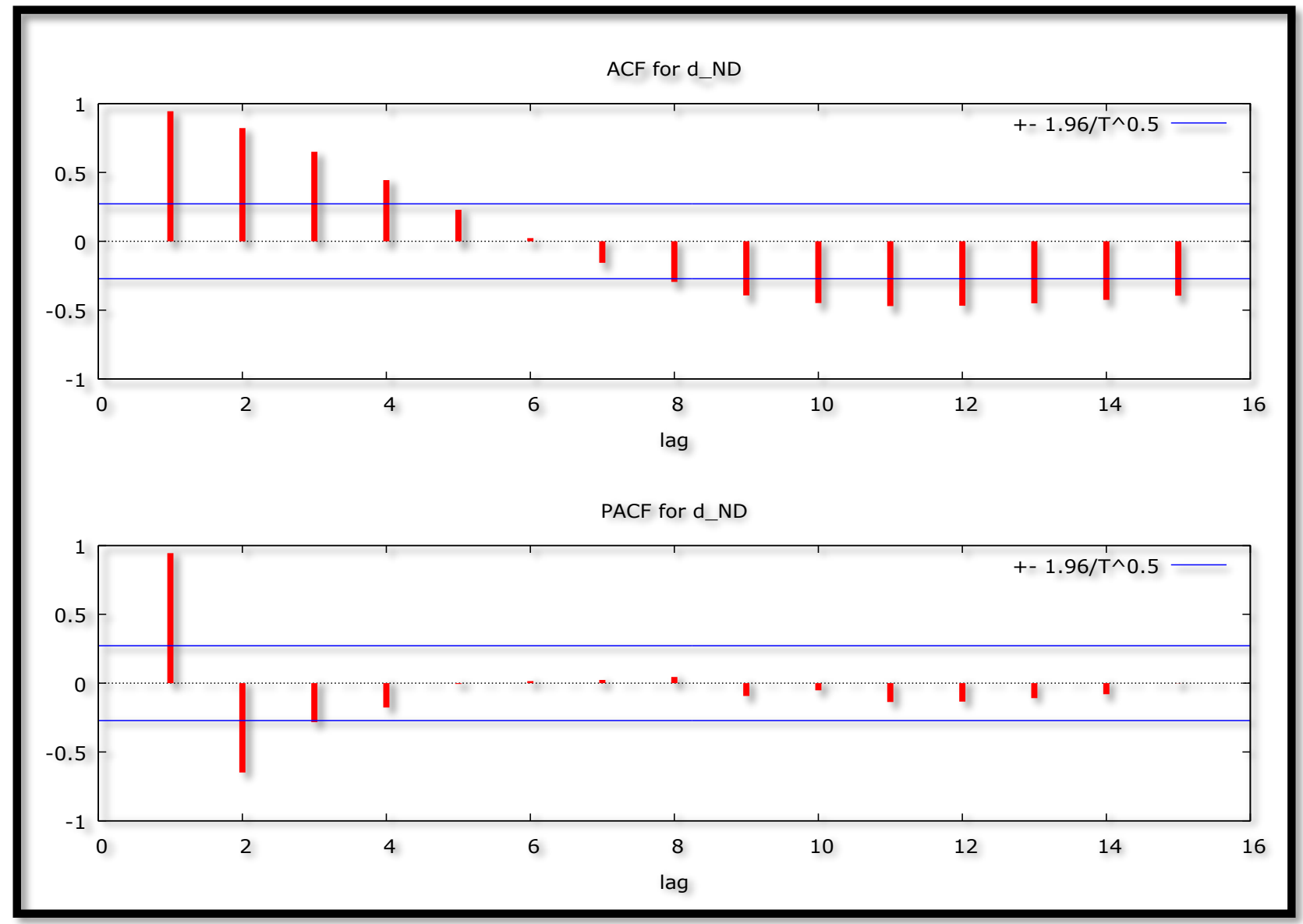

Figure 3

Table 4: $1^{\text {st }}$ Difference-intercept

\begin{tabular}{|l|l|l|l|l|l|}
\hline Variable & ADF Statistic & Probability & Critical Values & Conclusion \\
\hline ND & -3.084520 & 0.0343 & -3.571310 & $@ 1 \%$ & Not stationary \\
\hline & & -2.922449 & $@ 5 \%$ & Stationary \\
\hline & & -2.599224 & $@ 10 \%$ & Stationary \\
\hline
\end{tabular}

Table 5: $1^{\text {st }}$ Difference-trend \& intercept

\begin{tabular}{|c|c|c|c|c|c|}
\hline \multirow{2}{*}{$\begin{array}{l}\text { Variable } \\
\text { ND }\end{array}$} & ADF Statistic & Probability & \multicolumn{2}{|c|}{ Critical Values } & Conclusion \\
\hline & -3.135578 & 0.1097 & -4.156734 & @1\% & Not stationary \\
\hline & & & -3.504330 & $@ 5 \%$ & Not stationary \\
\hline & & & -3.181826 & @10\% & Not stationary \\
\hline
\end{tabular}

Table 6: $1^{\text {st }}$ Difference-without intercept and trend \& intercept

\begin{tabular}{|l|l|l|l|l|l|}
\hline Variable & ADF Statistic & Probability & Critical Values & Conclusion \\
\hline ND & -3.071985 & 0.0028 & -2.613010 & $@ 1 \%$ & Stationary \\
\hline & & -1.947665 & $@ 5 \%$ & Stationary \\
\hline & & -1.612573 & $@ 10 \%$ & Stationary \\
\hline
\end{tabular}

Figures above, that is; 2 and 3 and tables above, that is; 1 to 6 show that the ND series is not stationary in levels and even after taking first differences. 


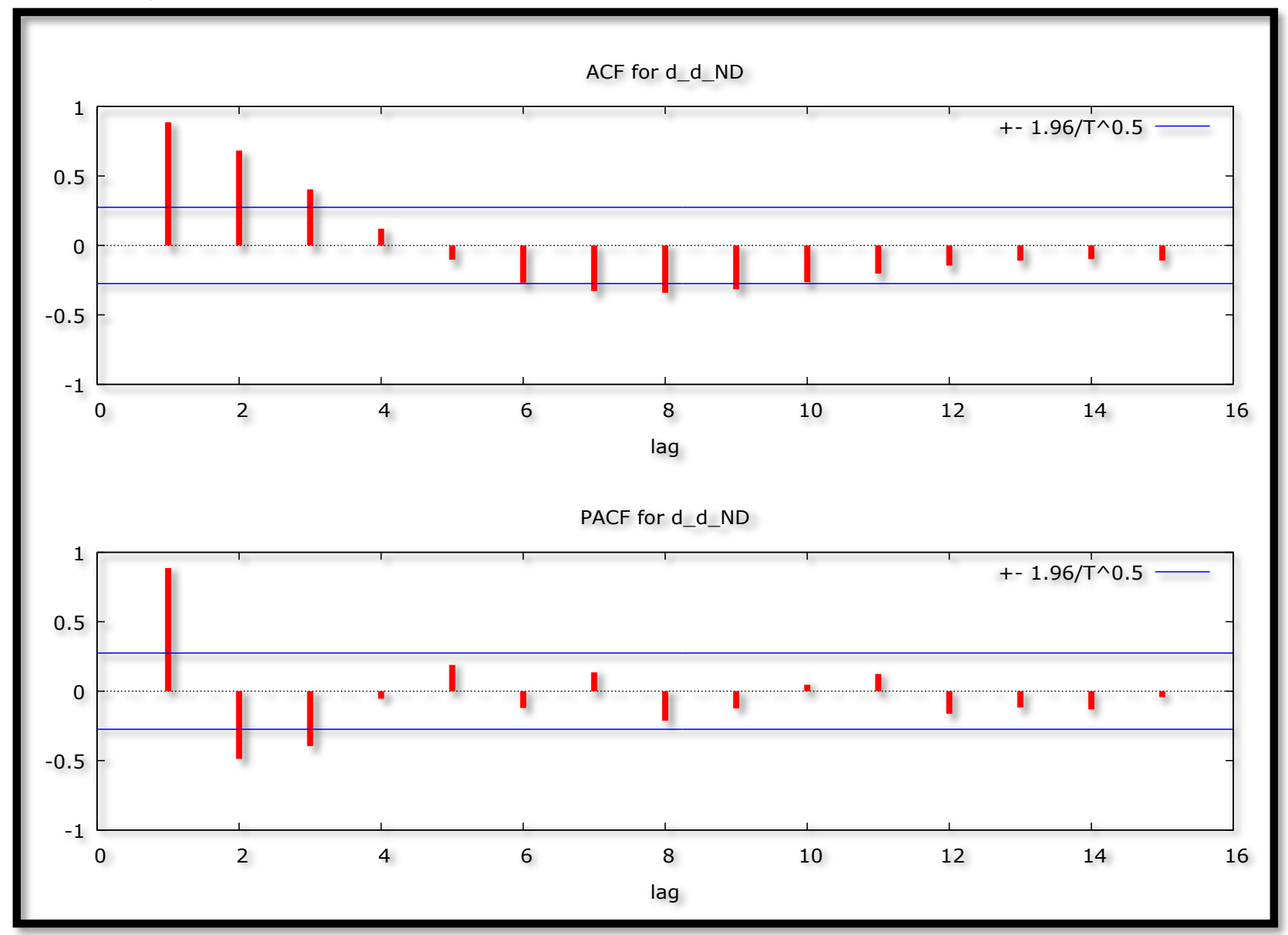

Figure 4

Table 7: $2^{\text {nd }}$ Difference-intercept

\begin{tabular}{|c|c|c|c|c|c|}
\hline Variable & ADF Statistic & Probability & \multicolumn{2}{|c|}{ Critical Values } & Conclusion \\
\hline ND & -3.675517 & 0.0076 & -3.574446 & @1\% & Stationary \\
\hline & & & -2.923780 & $@ 5 \%$ & Stationary \\
\hline & & & -2.599925 & @ 10\% & Stationary \\
\hline
\end{tabular}

Table 8: $2^{\text {nd }}$ Difference-trend \& intercept

\begin{tabular}{|l|l|l|l|l|l|}
\hline Variable & ADF Statistic & Probability & Critical Values & Conclusion \\
\hline ND & -3.551269 & 0.0452 & -4.161144 & $@ 1 \%$ & Not stationary \\
\hline & & -3.506374 & @ 5\% & Stationary \\
\hline & & -3.183002 & $@ 10 \%$ & Stationary \\
\hline
\end{tabular}

Table 9: $2^{\text {nd }}$ Difference-without intercept and trend \& intercept

\begin{tabular}{|c|c|c|c|c|c|}
\hline Variable & ADF Statistic & Probability & \multicolumn{2}{|c|}{ Critical Values } & Conclusion \\
\hline ND & -3.656290 & 0.0005 & -2.614029 & @1\% & Stationary \\
\hline & & & -1.947816 & @ 5\% & Stationary \\
\hline & & & -1.612492 & @ 10\% & Stationary \\
\hline
\end{tabular}

Figure 4 and tables $7-9$ illustrate that the ND series is I (2). 
Evaluation of ARIMA models (without a constant)

Table 10: Evaluation of ARIMA Models

\begin{tabular}{|l|l|l|l|l|l|l|}
\hline Model & AIC & $\mathrm{U}$ & ME & MAE & RMSE & MAPE \\
\hline ARIMA $(1,2,1)$ & 508.8748 & 0.094273 & 0.13639 & 26.505 & 33.009 & 0.26106 \\
\hline ARIMA $(1,2,0)$ & 519.8532 & 0.10747 & 0.18166 & 30.387 & 37.611 & 0.29746 \\
\hline ARIMA $(0,2,1)$ & 548.4842 & 0.13613 & -5.7155 & 36.803 & 49.579 & 0.35169 \\
\hline ARIMA $(2,2,2)$ & 498.1694 & 0.083948 & -1.3455 & 24.151 & 28.506 & 0.23913 \\
\hline ARIMA $(2,2,1)$ & 497.0830 & 0.084895 & -1.5782 & 23.865 & 28.766 & 0.2369 \\
\hline ARIMA $(3,2,1)$ & 498.5739 & 0.08457 & -1.5579 & 24.048 & 28.622 & 0.23863 \\
\hline ARIMA $(1,2,3)$ & 499.0258 & 0.082422 & -0.1567 & 23.625 & 28.741 & 0.23271 \\
\hline ARIMA $(3,2,3)$ & 497.6955 & 0.07881 & -1.1237 & 22.872 & 27.254 & 0.22513 \\
\hline ARIMA $(2,2,0)$ & 499.6099 & 0.087145 & -0.67409 & 23.98 & 30.075 & 0.23675 \\
\hline ARIMA $(0,2,3)$ & 503.4351 & 0.087326 & -1.8571 & 23.997 & 30.595 & 0.23377 \\
\hline ARIMA $(3,2,0)$ & 496.7449 & 0.08461 & -1.4581 & 24.097 & 28.669 & 0.23892 \\
\hline ARIMA $(2,2,3)$ & 498.0951 & 0.079599 & -0.56861 & 23.234 & 27.871 & 0.227 \\
\hline ARIMA $(3,2,2)$ & 500.1682 & 0.083919 & -1.3311 & 24.15 & 28.506 & 0.23909 \\
\hline ARIMA $(4,2,0)$ & 498.3876 & 0.084461 & -1.6254 & 23.972 & 28.571 & 0.23801 \\
\hline ARIMA $(5,2,0)$ & 498.4799 & 0.082455 & -1.3021 & 23.903 & 28.036 & 0.23686 \\
\hline ARIMA $(6,2,0)$ & 496.6646 & 0.080052 & -1.3377 & 22.345 & 26.988 & 0.22224 \\
\hline ARIMA $(7,2,0)$ & 497.6298 & 0.079164 & -1.4038 & 21.839 & 26.712 & 0.21697 \\
\hline ARIMA $(8,2,0)$ & 495.5793 & 0.074962 & -1.2423 & 20.218 & 25.727 & 0.19847 \\
\hline ARIMA $(9,2,0)$ & 496.8071 & 0.073258 & -1.136 & 20.158 & 25.514 & 0.19756 \\
\hline ARIMA $(10,2,0)$ & 496.9803 & 0.073258 & -1.136 & 20.175 & 25.021 & 0.19801 \\
\hline ARIMA $(8,2,1)$ & 497.2608 & 0.07469 & -1.2035 & 20.12 & 25.643 & 0.19726 \\
\hline ARIMA $(6,2,1)$ & 496.6081 & 0.078026 & -1.4242 & 21.282 & 26.462 & 0.21073 \\
\hline
\end{tabular}

A model with a lower AIC value is better than the one with a higher AIC value (Nyoni, 2018b) Similarly, the $\mathrm{U}$ statistic can be used to find a better model in the sense that it must lie between 0 and 1 , of which the closer it is to 0 , the better the forecast method (Nyoni, 2018a). In this paper, only the AIC is used to select the optimal model. Therefore, the ARIMA $(8,2,0)$ model is chosen.

Residual \& Stability Tests

ADF Tests of the Residuals of the ARIMA (8, 2, 0) Model

Table 11: Levels-intercept

\begin{tabular}{|c|c|c|c|c|c|}
\hline Variable & ADF Statistic & Probability & \multicolumn{2}{|c|}{ Critical Values } & Conclusion \\
\hline \multirow{3}{*}{$\mathrm{R}$} & -6.595173 & 0.0000 & -3.596616 & @1\% & Stationary \\
\hline & & & -2.933158 & @ 5\% & Stationary \\
\hline & & & -2.604867 & @10\% & Stationary \\
\hline
\end{tabular}

Table 12: Levels-trend \& intercept

\begin{tabular}{|l|l|l|l|l|l|}
\hline Variable & ADF Statistic & Probability & Critical Values & Conclusion \\
\hline $\mathrm{R}$ & -6.521314 & 0.0000 & -4.192337 & @ 1\% & Stationary \\
\hline & & -3.520787 & $@ 5 \%$ & Stationary \\
\hline & & -3.191277 & $@ 10 \%$ & Stationary \\
\hline
\end{tabular}

Table 13: without intercept and trend \& intercept

\begin{tabular}{|c|c|c|c|c|c|}
\hline Variable & ADF Statistic & Probability & \multicolumn{2}{|c|}{ Critical Values } & Conclusion \\
\hline $\mathrm{R}$ & -6.651100 & 0.0000 & -2.621185 & @ 1\% & Stationary \\
\hline & & & -1.948886 & @5\% & Stationary \\
\hline & & & -1.611932 & @ 10\% & Stationary \\
\hline
\end{tabular}

Tables 11 - 13 indicate that the residuals of the chosen optimal model, the ARIMA $(8,2,0)$ model; are stationary. 


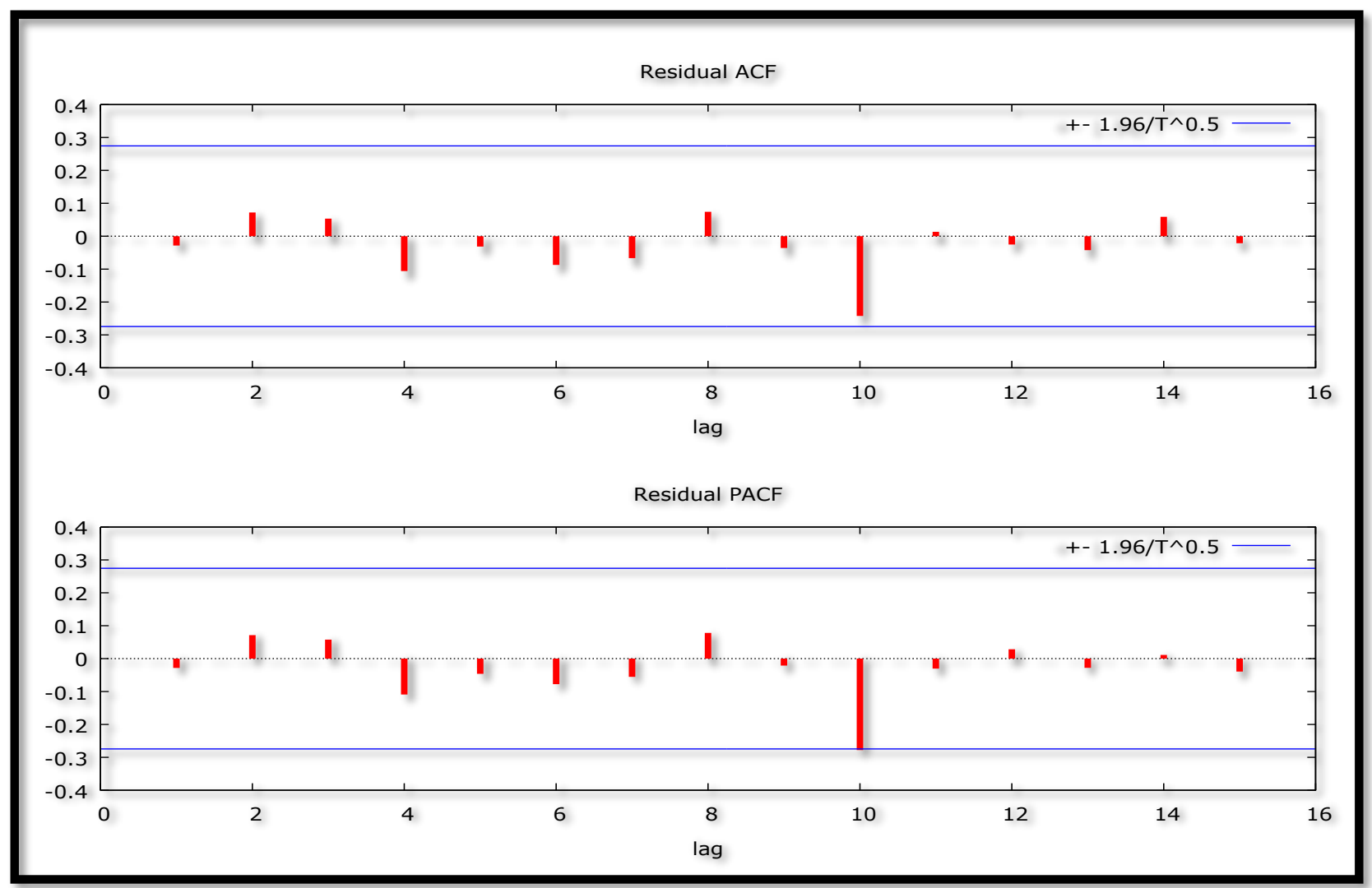

Figure 5: Correlogram of the Residuals

Figure 5 indicates that the estimated model is adequate since $\mathrm{ACF}$ and PACF lags are quite short and within the bands. This implies that the no autocorrelation assumption is not violated in this study.

\section{Test for Normality of Residuals}

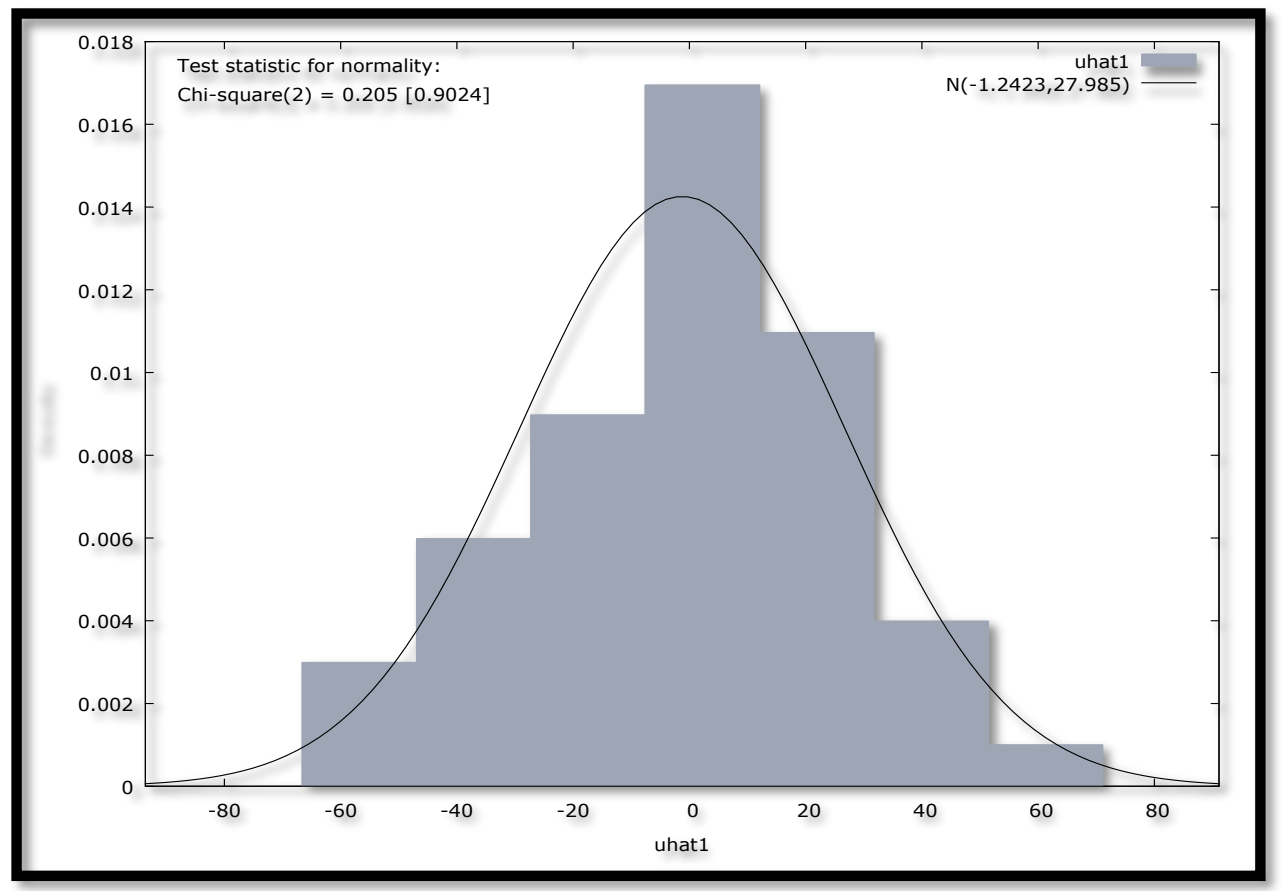

Figure 6: Normality Test

Since the p-value, that is; [0.9024] is statistically insignificant, it implies that the residuals are normally distributed, hence the validity of the normality assumption.

Stability Test of the ARIMA $(8,2,0)$ Model 


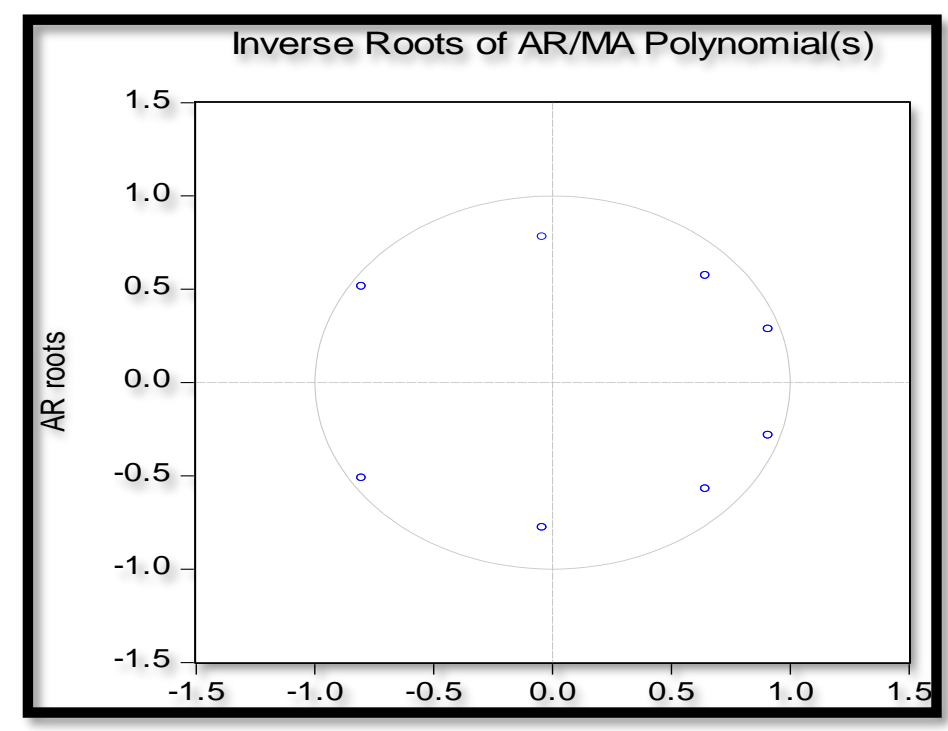

Figure 7: Inverse Roots

Since all the AR roots lie inside the unit circle, it implies that the estimated ARIMA process is (covariance) stationary; thus confirming that the ARIMA $(8,2,0)$ model is indeed stable and suitable for forecasting annual neonatal deaths in Zimbabwe.

\section{Descriptive Statistics}

\section{FINDINGS}

Table 14: Descriptive Statistics

\begin{tabular}{|l|l|}
\hline Description & Statistic \\
\hline Mean & 9927 \\
\hline Median & 9696 \\
\hline Minimum & 7361 \\
\hline Maximum & 13169 \\
\hline Standard deviation & 1503.5 \\
\hline Skewness & 0.51971 \\
\hline Excess kurtosis & -0.48186 \\
\hline
\end{tabular}

As shown above, the mean is positive, i.e. 9927. This means that the average number of neonatal deaths over the study period is 9927 deaths per annum. The minimum number of neonatal deaths over the study period is 7361 deaths and this was recorded in 1961 while the maximum number of neonatal deaths is 13169 deaths and this was recorded in 2010. The skewness is 0.51971 and the most important characteristic is that it is positive, meaning that the ND series is positively skewed and non-symmetric. Excess kurtosis is -0.48186 ; showing that the ND series is not normally distributed.

\section{Results Presentation}

Table 15: Main Results

\begin{tabular}{|c|c|c|c|c|}
\hline \multicolumn{5}{|c|}{ 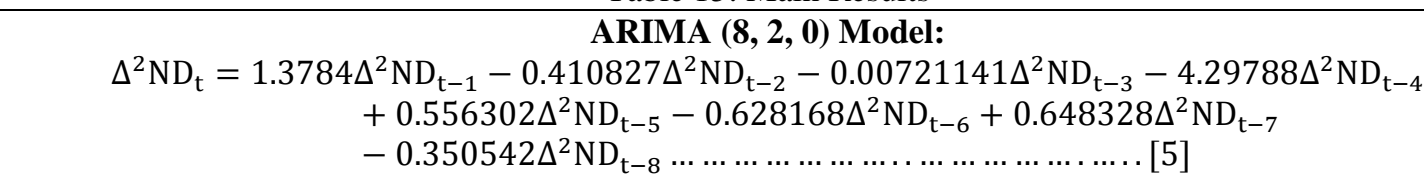 } \\
\hline Variable & Coefficient & Standard Error & $\mathrm{z}$ & p-value \\
\hline$\emptyset_{1}$ & 1.37840 & 0.130935 & 10.53 & $0.0000^{* * *}$ \\
\hline$\emptyset_{2}$ & -0.410827 & 0.222244 & -1.849 & $0.0645^{*}$ \\
\hline$\emptyset_{3}$ & -0.00721141 & 0.229988 & -0.03136 & 0.9750 \\
\hline$\emptyset_{4}$ & -0.429788 & 0.225863 & -1.903 & $0.0571 *$ \\
\hline$\emptyset_{5}$ & 0.556302 & 0.217560 & 2.557 & $0.0106^{* * *}$ \\
\hline$\emptyset_{6}$ & -0.628168 & 0.232070 & -2.707 & $0.0068 * * *$ \\
\hline$\emptyset_{7}$ & 0.648328 & 0.261209 & 2.482 & $0.0131 * *$ \\
\hline$\emptyset_{8}$ & -0.350542 & 0.168886 & -2.076 & $0.0379 * *$ \\
\hline
\end{tabular}

Forecast Graph 


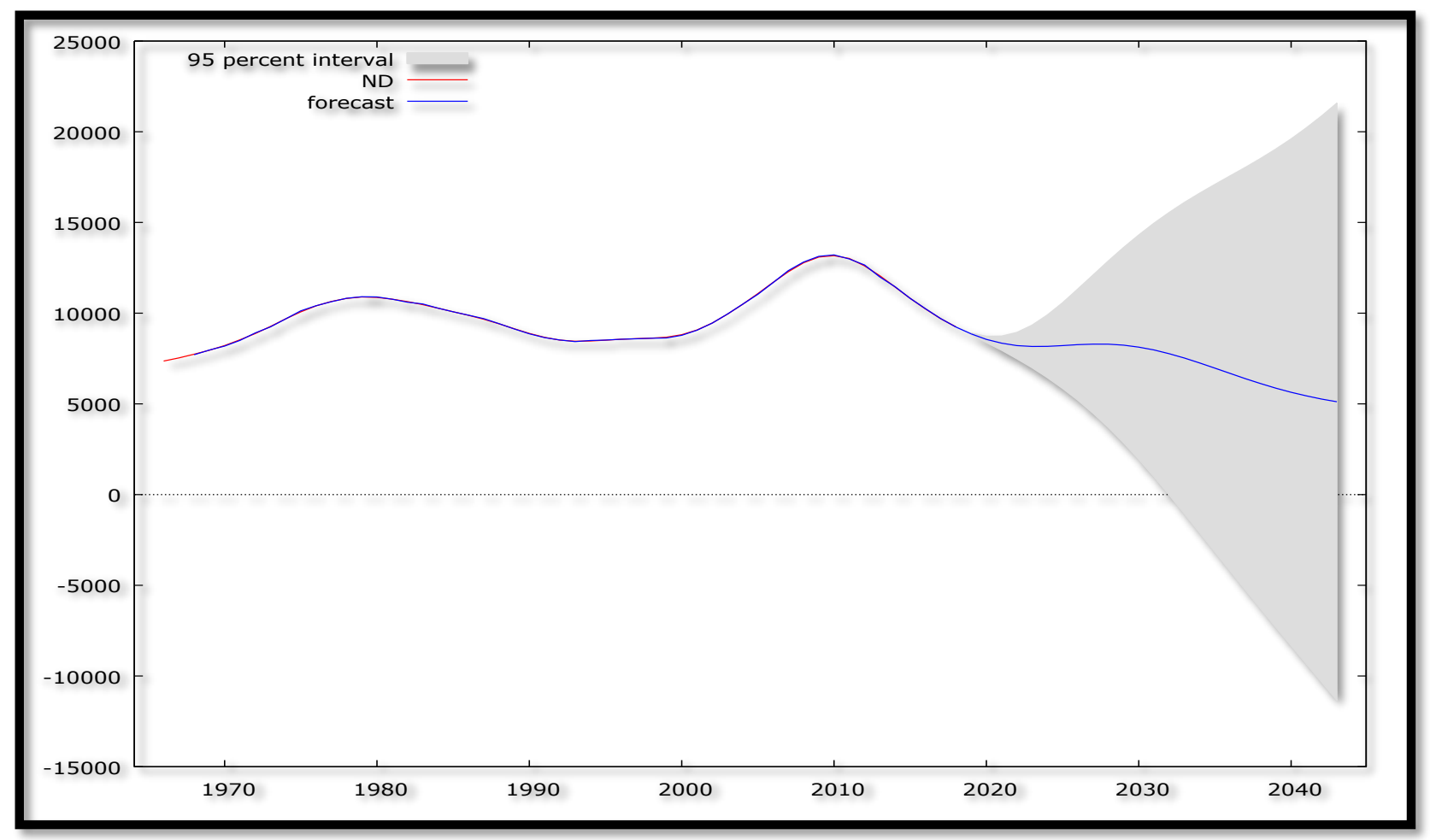

Figure 8: Forecast Graph - In \& Out-of-Sample Forecasts

Table 18: Tabulated Out-of-Sample Forecasts

\begin{tabular}{|l|l|l|l|}
\hline Year & Predicted Neonatal Deaths & Standard Error & 95\% Confidence Interval \\
\hline 2019 & 8859.80 & 24.8870 & $(8811.02,8908.58)$ \\
\hline 2020 & 8553.55 & 87.6841 & $(8381.69,8725.40)$ \\
\hline 2021 & 8346.06 & 200.518 & $(7953.05,8739.07)$ \\
\hline 2022 & 8211.26 & 372.053 & $(7482.05,8940.47)$ \\
\hline 2023 & 8164.11 & 600.245 & $(6987.65,9340.57)$ \\
\hline 2024 & 8171.63 & 882.005 & $(6442.93,9900.33)$ \\
\hline 2025 & 8210.95 & 1206.25 & $(5846.74,10575.2)$ \\
\hline 2026 & 8266.03 & 1562.64 & $(5203.31,11328.8)$ \\
\hline 2027 & 8292.83 & 1943.14 & $(4484.36,12101.3)$ \\
\hline 2028 & 8291.30 & 2338.84 & $(3707.27,12875.3)$ \\
\hline 2029 & 8236.43 & 2744.64 & $(2857.03,13615.8)$ \\
\hline 2030 & 8127.77 & 3154.88 & $(1944.31,14311.2)$ \\
\hline 2031 & 7972.78 & 3565.74 & $(984.069,14961.5)$ \\
\hline 2032 & 7764.39 & 3974.40 & $(-25.2893,15554.1)$ \\
\hline 2033 & 7525.82 & 4377.97 & $(-1054.84,16106.5)$ \\
\hline 2034 & 7255.30 & 4776.08 & $(-2105.64,16616.2)$ \\
\hline 2035 & 6968.58 & 5168.57 & $(-3161.64,17098.8)$ \\
\hline 2036 & 6679.16 & 5557.07 & $(-4212.49,17570.8)$ \\
\hline 2037 & 6389.13 & 5944.14 & $(-5261.16,18039.4)$ \\
\hline 2038 & 6118.77 & 6332.44 & $(-6292.59,18530.1)$ \\
\hline 2039 & 5865.56 & 6725.60 & $(-7316.37,19047.5)$ \\
\hline 2040 & 5639.28 & 7126.32 & $(-8328.06,19606.6)$ \\
\hline 2041 & 5441.76 & 7537.39 & $(-9331.25,20214.8)$ \\
\hline 2042 & 5266.27 & 7960.91 & $(-10336.8,20869.4)$ \\
\hline 2043 & 5117.03 & 8398.09 & $(-11342.9,21577.0)$ \\
\hline & & & \\
\hline & & & \\
\hline
\end{tabular}

\section{Predicted ND}




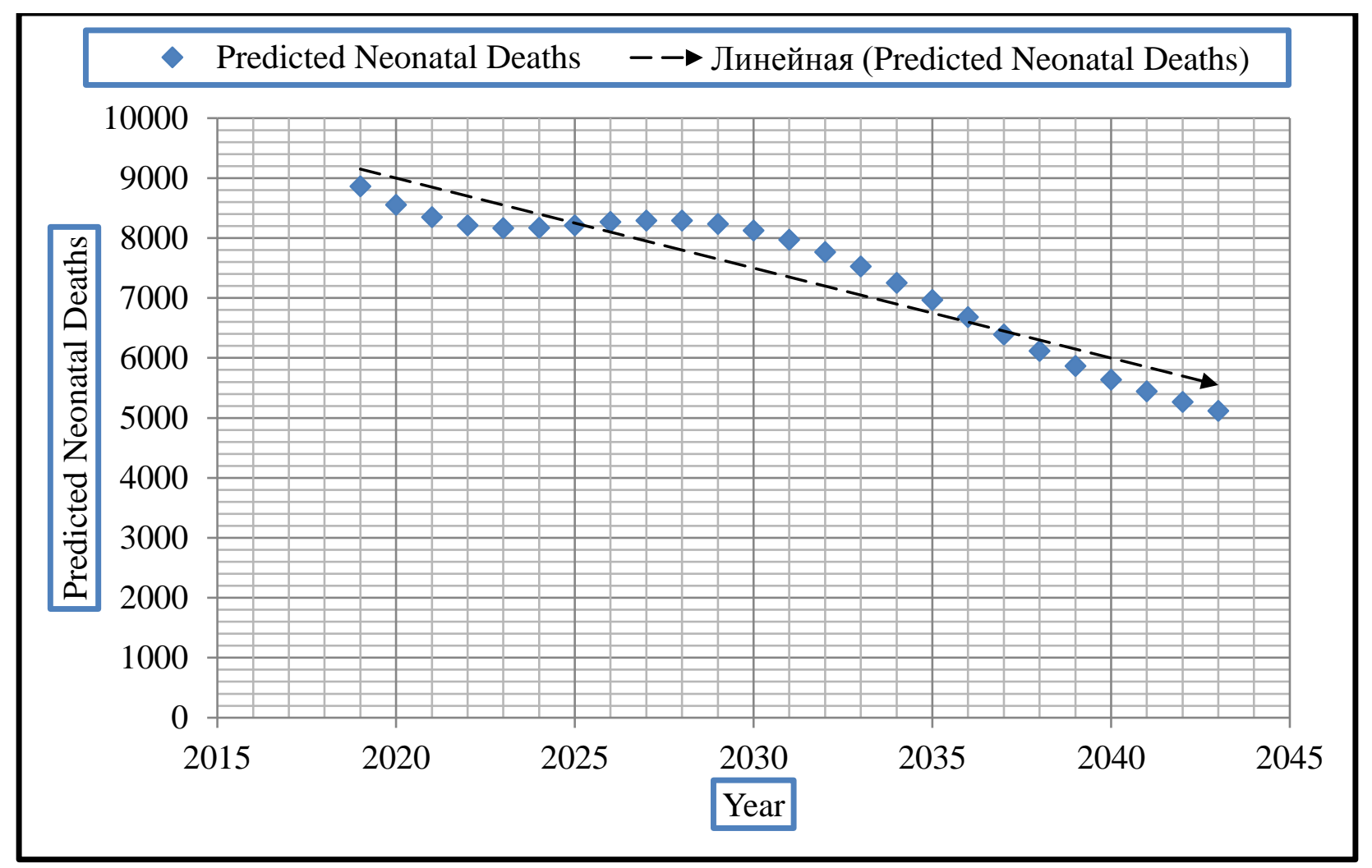

Figure 9: Graphical Analysis of Out-of-Sample Forecasts

Table 15 shows the main results of the ARIMA $(8,2,0)$ model. Figure 8 and 9 as well as table 18 are out-of-sample forecasts of the ARIMA $(8,2,0)$ model. As clearly shown in figure 9 , the number of neonatal deaths per year, over the out-of-sample period, show a sharply downwards trend. This is encouraging and commendable, for a developing country like Zimbabwe. These results are consistent with Nyoni \& Nyoni (2020).

\section{Policy Implications}

i. The government of Zimbabwe should continue to intensify training programs in resuscitation and in essential newborn care in order to maintain low levels of and or eradicate neonatal deaths.

ii. The government of Zimbabwe should work towards improving access to healthcare services through out the whole country.

iii. The government of Zimbabwe should also work toward capacity building in virtually all public health institutions in the country to ensure that comprehensive neonatal care services are offered country-wide.

iv. The government of Zimbabwe should encourage and promote consistent home visits by community health workers, for neonatal care.

\section{CONCLUSION}

The study shows that the ARIMA $(8,2,0)$ model is not only stable but also the most suitable model to forecast neonatal deaths in Zimbabwe for the next 25 years. The model predicts a sharp decrease in neonatal deaths in Zimbabwe. Such a trend should be maintained and in this regard, a four-fold policy prescription has been offered. These findings are essential for the government of Zimbabwe, especially when it comes to longterm planning with regards to neonatal care in the country.

\section{REFERENCES}

1. Asteriou, D. \& Hall, S. G. (2007). Applied Econometrics: a modern approach, Revised Edition, Palgrave MacMillan, New York.

2. Babaei, H., Dehghan, M., \& Pirkashani, L. M. (2018). Study of Causes of Neonatal Mortality and Its Related Factors in the Neonatal Intensive Care Unit of Iman Reza Hospital in Kermanshah during (2014 - 2016), International Journal of Pediatrics, 6 (5): 7641 - 7649.

3. Box, G. E. P., \& Jenkins, G. M. (1970). Time Series Analysis: Forecasting and Control, Holden Day, San Francisco.

4. Carlo, W. A., \& Travers, C. P. (2016). Maternal and Neonatal Mortality: Time To Act, Journal of Pediatrics, 92 (6): $543-545$. 
5. Chaibva, B. V., Olorunju, S., Nyadundu, S., \& Beke, A. (2019). Adverse Pregnancy Outcomes "Stillbirth and Early Neonatal Deaths" in Mutare District, Zimbabwe (2014): A Descriptive Study, BMC Pregnancy and Childbirth, 19 (86): $1-7$

6. Chengye, J. (2012). Child and Adolescent Health, People's Medical Publishing House, Beijing.

7. du Preez, J. \& Witt, S. F. (2003). Univariate and multivariate time series forecasting: An application to tourism demand, International Journal of Forecasting, 19: 435 - 451.

8. Ezeh, O. K., Agho, K. E., Dibley, M. J., Hall, J., \& Page, A. N. (2014). Determinants of Neonatal Mortality in Nigeria: Evidence From the 2008 Demographic and Health Survey, BMC Public Health, 14: 521 - 531.

9. Kanyenze, G., Chitambara, P., \& Tyson, J. (2017). The Outlook For The Zimbabwean Economy, Supporting Economic Transformation (SET), Harare.

10. Khan, M. S., Fatima, S., Zia, S. S., Hussain, E., Faraz, T. R., \& Khalid, F. (2019). Modeling and Forecasting Infant Mortality Rates of Asian Countries in the Perspective of GDP (PPP), International Journal of Scientific and Engineering Research, 10 (3): $18-23$.

11. Lawn, J. E., Cousens, S., \& Zupan, J. (2005). Neonatal Survival 1:4 Million Deaths: When? Where? Where? Why? Neonatal Survival Series Paper 1, Lancet, 365: 891 - 900.

12. Ministry of Health and Child Care (2007). The Zimbabwe National Maternal and Neonatal Health Road Map (2007-2015), Government of Zimbabwe, Harare.

13. Mishra, A. K., Sahanaa, C., \& Manikandan, M. (2019). Forecasting Indian Infant Mortality Rate: An Application of Autoregressive Integrated Moving Average Model, Journal of Family and Community Medicine, 26: 123 - 126.

14. Nouri, A., Barati, L., Qhezelsofly, F., \& Niazi, S. (2013). Causes of Infant Mortality in Kalaleh City During 2004 - 2012, Hakim Jorjani Journal, 1 (2): 2 - 37.

15. Nyoni, S. P., \& Nyoni, T. (2020). ARIMA Modeling of Neonatal Mortality in Chitungwiza Central Hospital, International Journal of Multidisciplinary Research (IJMR), 6 (2): 189 - 196.

16. Nyoni, T (2018b). Modeling and Forecasting Inflation in Kenya: Recent Insights from ARIMA and GARCH analysis, Dimorian Review, 5 (6): 16 - 40.

17. Nyoni, T. (2018a). Modeling and Forecasting Naira/USD Exchange Rate in Nigeria: A Box-Jenkins ARIMA Approach, MPRA Paper No. 88622, University Library of Munich, Munich.

18. Nyoni, T. (2018c). Box - Jenkins ARIMA Approach to Predicting net FDI inflows in Zimbabwe, MPRA Paper No. 87737, University Library of Munich, Munich.

19. Nyoni, T. (2019). Maternal Deaths in Zimbabwe: Is it a Crime to be a Woman in Zimbabwe? MPRA Paper No. 96789, University Library of Munich, Munich.

20. Rajaratnam, J. K., Marcus, J. R., \& Flaxman, A. D. (2010). Neonatal, postnatal, childhood and under-5 mortality for 187 countries, 1970 - 2010: A Systematic Analysis of Progress Towards Millennium Development Goal 4, Lancet, 375: 1988 - 2008.

21. Sarpong, S. A. (2013). Modeling and Forecasting Maternal Mortality; An Application of ARIMA Models, International Journal of Applied Science and Technology, 3 (1): $19-28$.

22. Song, H., Witt, S. F. \& Jensen, T. C. (2003b). Tourism forecasting: accuracy of alternative econometric models, International Journal of Forecasting, 19: $123-141$.

23. Tachiwenyika, E., Gombe, N., Shambira, G., Chadambuka, A., Tshimanga, M., \& Zizhou, S. (2011). Determinants of Perinatal Mortality in Marondera District, Mashonaland East Province of Zimbabwe, 2009: a Case Control Study, Pan African Medical Journal, pp: $1-8$.

24. UNICEF (2008). The State of the World's Children, Child Survival-UNICEF.

25. UNICEF (2017). The neonatal period is the most vulnerable time for a child. http://data.unicef.org/childmortality/neonatal.html ; accessed 29/01/2020.

26. Usman, A., Sulaiman, M. A., \& Abubakar, I. (2019). Trend of Neonatal Mortality In Nigeria From 1990 to 2017 Using Time Series Analysis, Journal of Applied Sciences and Environmental Management, 23 (5): 865 $-869$. 